\title{
Clinical utility of guanfacine extended release in the treatment of ADHD in children and adolescents
}

This article was published in the following Dove Press journal:

Patient Preference and Adherence

30 June 2015

Number of times this article has been viewed

\author{
Nicholas T Bello \\ Department of Animal Sciences, \\ Rutgers, The State University of New \\ Jersey, New Brunswick, NJ, USA
}

\begin{abstract}
Attention deficit hyperactivity disorder (ADHD) is the most common psychiatric illness in children and adolescents. Several stimulant medications, such as methylphenidate and amphetamine derivatives, are available to treat ADHD in pediatric patients. Nonstimulant medications are more preferred by some parents, other caregivers, and patients because they lack the abuse potential of stimulant medications. In the US, one available nonstimulant option is guanfacine extended release (XR). As a selective $\alpha_{2 \mathrm{~A}}$ adrenergic receptor, guanfacine acts on the central noradrenergic pathways and cortical noradrenergic targets to improve working memory and attention. The XR formulation of guanfacine, compared with the immediate-release formulation, is more effective for the long-term management of ADHD and is associated with fewer adverse effects. Available data also indicate that guanfacine XR is superior to atomoxetine and is as effective as the nonselective $\alpha_{2}$ adrenergic receptor agonist, clonidine XR. The most common adverse effects associated with guanfacine XR are somnolence, fatigue, bradycardia, and hypotension. Somnolence is the most often cited reason for discontinuation. Guanfacine XR is also labeled for use as an adjuvant to stimulant treatment for ADHD. A similar profile of adverse effects as reported with monotherapy is reported when guanfacine XR is "added on" to stimulant therapy with somnolence as the most commonly reported adverse event. This review discusses the clinical efficacy and patient preference of guanfacine XR based on available published data on the safety, relative effectiveness, and tolerance of this medication to treat ADHD.
\end{abstract}

Keywords: Intuniv, norepinephrine, prefrontal cortex, locus coeruleus, impulsivity, inattentive

\section{Introduction}

Attention deficit hyperactivity disorder (ADHD) is one of the most commonly diagnosed neurodevelopmental psychiatric disorders. ${ }^{1,2}$ While ADHD can be present and diagnosed in adulthood, the age of onset in childhood is before 12 years of age. ${ }^{3,4}$ There are three subtypes of ADHD based on the reported presentation of attentive and/or impulsive behaviors. In children and adolescents, $\sim 50 \%$ of the diagnosed cases of ADHD are of the inattentive subtype (ADHD-I), which is characterized by a failure of sustained attention as well as disorganization and high distractibility. The hyperactivity/impulsivity subtype (ADHD-H) is seen in $\sim 15 \%$ of those children and adolescents diagnosed with ADHD. Children with the ADHD-H subtype have a high degree of restlessness, talk excessively, and are often interruptive. Approximately $33 \%$ of the cases of ADHD have the combined hyperactivity/impulsivity and inattentive subtype (ADHD-C). ${ }^{3,5}$ The combined subtype presents with both criteria of ADHD-I and ADHD-H. ${ }^{3}$ Boys are much more likely to present with symptoms of ADHD than girls. In fact, for all three subtypes, there is at
Correspondence: Nicholas T Bello Department of Animal Sciences, School of Environmental and Biological Sciences, Rutgers, The State University of New Jersey, 84 Lipman Drive, New Brunswick, NJ 0890I, USA

Tel +l 8489322966

Fax +I 7329326996

Email ntbello@aesop.rutgers.edu 
least a 3:1 male-to-female ratio. ${ }^{3,6,7}$ The prevalence of ADHD has been conservatively estimated to be $3.4 \%-5 \%$ in children and adolescents. ${ }^{3,8}$ While the variation in prevalence between countries seems to be minimal and has been attributed to differences in regional diagnostic practices, ${ }^{8,9}$ differences between races and ethnicities in US populations have been noted. ${ }^{6,10}$ Family socioeconomic status has been more strongly associated with ADHD, with children from lower-income families at a greater long-term risk. ${ }^{6}$ Notably, there is high hereditability for ADHD. ${ }^{11}$ Hereditability, calculated from dizygotic and monozygotic twin studies, has been estimated to be $76 \%{ }^{12}$ An examination of parents $(\mathrm{n}=198)$ and siblings $(n=112)$ of adoptive $(n=25)$ and biological $(n=101)$ children diagnosed with ADHD revealed that the rate of ADHD was significantly higher in parents (18\%) and siblings (31\%) of the biologically related children with ADHD. The rate of ADHD in adoptive parents and siblings of ADHD children was similar to the rate of ADHD in parents and siblings of children without ADHD (ie, $3 \%-8 \%) .{ }^{13}$ Despite the strong implication of an inherited component to ADHD, neither single candidate gene nor genome-wide association studies have yet identified a target gene or set of genes strongly associated with ADHD. ${ }^{11}$ Nonetheless, the roles of rare copy number variants and linkage studies in ADHD are still emerging. ${ }^{14}$ Two genes related to cadherins and their functions, $\mathrm{CDH} 13$ and CTNNA2, have been linked to ADHD in some genome-wide association studies. ${ }^{11,15}$ A study of subjects with $(\mathrm{n}=1,136)$ or without ( $\mathrm{n}=946$ ). ADHD examined the polymorphisms of CDH13 and CTNNA2 associated with ADHD-associated behaviors. In children and adolescents with ADHD, the CDH13 rs 11150556 (CC genotype) was linked $(P<0.006)$ to hyperactivity/impulsive behaviors. ${ }^{15}$ Based on the different subtypes, variations in the age of onset, and heterogeneous etiology of ADHD, it is clear that ADHD is a polygenic disorder in which many genes having a small individual effect contribute to the susceptibility and severity. As such, there are several factors that must be taken into account for successful management of the disorder and ensuring long-term adherence to treatment options for children and adolescents with ADHD. This review will examine the clinical utility and patient compliance of guanfacine extended release (XR) as a pharmacological treatment for ADHD as well as discuss, when available, how the measured outcomes compare with other treatment strategies.

\section{Neural pathways involved in ADHD}

Several brain pathways have been implicated in ADHD pathology. ${ }^{16,17}$ Two of the most studied neuromodulatory pathways are the midbrain dopamine (DA) and the locus coeruleus-norepinephrine (LC-NE) systems.

The midbrain DA system is regulated by a group of DA-containing neurons in the A10 and A9 regions that project to areas of the striatum, prefrontal cortex, and other areas of the limbic system. ${ }^{18,19}$ Two functions of the midbrain DA system is to mediate the neural correlates of reward and strengthen associations with reinforcing behaviors. ${ }^{20} \mathrm{~A}$ prevailing concept is that there is a midbrain DA dysfunction in ADHD that contributes to a steeper delay of reinforcement gradient. ${ }^{21}$ The delay of reinforcement gradient is based on the principle that association between stimulus and reward is time dependent. Performance is impaired in ADHD children when the time delay between reinforcer and behavioral response is longer. ${ }^{21}$ Using male children (7-12 years old) diagnosed with $(n=8)$ or without $(n=12)$ ADHD, Sagvolden et al examined the lever responses that cued a reward (ie, coins, marbles, erasers, or other trinkets). ADHD children had increased lever responding toward the end of 30 seconds in each of the five fixed intervals during the acquisition phase, indicative of hyperactivity, as well as more burst lever pressing, interpreted as increased impulsivity. ${ }^{22}$ Along these lines, in reward comparison studies, children with ADHD will take the immediate small reward over the delayed larger reward (ie, choice-delay task). ${ }^{23}$ A preference for immediate small rewards has been associated with the higher inattentive ratings. ${ }^{23}$ Several imaging studies have further implicated the midbrain DA system and respective target regions with impaired reward processing in children with ADHD. ${ }^{24,25}$ The norepinephrine controls of attention are mediated by a group of neurons in the $\mathrm{A} 6$ region of the brainstem, also known as the LC-NE system. The LC-NE system is the primary source of norepinephrine in the cortex, hippocampus, and cerebellum. ${ }^{26}$ The LC-NE system has been implicated in attentional states, emotion, sleep, and adaptive aspects of stress reactivity. ${ }^{27-29}$ In response to salient stimuli to focus attention, LC-NE neurons fire phasically..$^{30}$ ADHD-related alterations in LC-NE activity suggest an increased tonic firing and reduced signal-to-noise ratio of LC neurons, which contribute to the inability to sustain focused attention. ${ }^{27,31,32}$ The NE transporter (NET) is a presynaptic solute transporter responsible for the reuptake of extracellular NE in brain regions and as such can modulate NE neural signaling. In brain regions that have low levels of the dopamine transporter (DAT), such as the prefrontal cortex, the NET is responsible for the reuptake of extracellular DA. ${ }^{33,34} \mathrm{In}$ a positron emission tomography (PET) study by Vanicek et al, a selective NET ligand $(S, S)-\left[{ }^{18} \mathrm{~F}\right]$ FMeNER-D2 
$\left((S, S)-2-\left(\alpha-\left(2-\left[{ }^{18} \mathrm{~F}\right]\right.\right.\right.$ fluoro $\left[{ }^{2} \mathrm{H}_{2}\right]$ methoxyphenoxy) benzyl) morpholine) was used to determine NET availability and regional distribution in adults with $(\mathrm{n}=22)$ or without $(\mathrm{n}=22)$ ADHD. ${ }^{35}$ Several subcortical areas were regions of interest, including the cerebellum, hippocampus, midbrain, striatum, thalamus, and locus coeruleus. Between ADHD (subtypes not distinctly classified) and control subjects, there were no differences in NET-binding potential or distribution. There was, however, an age-related decrease in NET availability in older individuals in the thalamus and the pons/midbrain; a similar age-related decrease in NET availability has been demonstrated by others. ${ }^{36}$ This PET imaging study by Vanicek et al suggests that NET is not different between ADHD and controls; however, due to artifacts produced by the frontal bones, the resolution of PET is only reliable for subcortical regions..$^{35}$ In addition, this study was performed in an adult population with ADHD. Considering the agerelated difference in NET, understanding the exact role of NET in cortical regions in children and adolescents with difference subtype classifications of ADHD remains to be determined.

\section{Pharmacological treatment options for ADHD \\ Stimulants}

Methylphenidate (methyl 2-phenyl-2-(piperidin-2-yl) acetate), also known as Ritalin ${ }^{\circledR}$ (Novartis International AG, Basel, Switzerland), is the most commonly prescribed medication for ADHD. Approved in 1955 for hyperactivity, methylphenidate is the oldest available FDA-approved medication for ADHD. Methylphenidate acts as a central nervous system (CNS) stimulant by binding to DAT and NET to increase synaptic levels of DA and norepinephrine. Using HEK 293 cells that stably express human DAT, NET, and the serotonin transporter, Simmler et al determined the in vitro binding affinities $\left(K_{i}\right)$ to be $0.06 \mu \mathrm{M}, 3.3 \mu \mathrm{M}$, and $21 \mu \mathrm{M}$, respectively. ${ }^{37}$ Despite the much higher in vitro potency for inhibiting DAT compared with NET, PET imaging studies have indicated that clinically relevant doses of methylphenidate bind to NET, but not serotonin transporter, in human subjects without ADHD. ${ }^{38,39}$ Methylphenidate is available in immediate-release or XR formulations. A meta-analysis of 13 randomly controlled trials (RCTs) compared immediate release with XR formulation in children and adolescents $(\mathrm{n}=882) .{ }^{40}$ In all 13 studies, reports from parents and/or teachers were used to assess the efficacy of treatment. Teacher reports indicated that immediate-release methylphenidate improved hyperactivity, whereas improvements in hyperactivity/impulsivity symptoms were indicated with XR in parent reports. There were no differences in reported adverse events between immediate and XR formulations. ${ }^{40}$ The most common adverse events associated with methylphenidate are anorexia, irritability, insomnia, and gastrointestinal-related events. ${ }^{40,41}$ Amphetamines (amphetamine [(RS)-1-phenylpropan-2-amine] and dextroamphetamines salts), such as Adderall ${ }^{\circledR}$ (Shire Pharmaceuticals, Dublin, Ireland), are also CNS stimulants commonly used to treat ADHD. Mixed amphetamine salts were approved by the FDA in 2001 for ADHD. By acting on the vesicular monoamine transporter 2 and trace amineassociated receptor 1 , amphetamine works to increase synaptic levels of DA, NE, and serotonin. ${ }^{42,43}$ Similar to methylphenidate, amphetamine is available in both immediate-release and XR formulations. One novel XR preparation is a prodrug, lisdexamfetamine dimesylate, which is a dextroamphetamine conjugated to the amino acid lysine. Blood peptidases are responsible for cleaving lysine from lisdexamfetamine and allowing for the sustained release of active dextroamphetamine. ${ }^{44}$ Although methylphenidate is often the first choice for treating ADHD in children and adolescents, a meta-analysis of four RCT compared immediate-release Adderall $(\mathrm{n}=108)$ and methylphenidate $(\mathrm{n}=108)$ preparations have reported a small, but significant superiority of immediate-release Adderall over methylphenidate ${ }^{45}$ The two medications in immediate-release formulations, however, have similar adverse events profiles. ${ }^{46}$ The prescription of amphetamine preparations rather than methylphenidate is dependent on the discretion of the prescriber, patient, or necessitated by the nonresponse to methylphenidate. Notably, immediate-release amphetamines and methylphenidate have the potential for misuse and abuse, which may be more of concern when treating adolescent patients. As such, XR (and prodrug) formulations have been suggested to have a lower abuse potential. ${ }^{47}$ Nonetheless, all amphetamine and methylphenidate formulations have an abuse potential and a DEA (USA) schedule II classification.

\section{Nonstimulants}

Atomoxetine ((-)- $N$-methyl-3-phenyl-3-(o-tolyloxy)propylamine hydrochloride), also known as Strattera ${ }^{\circledR}$ (Eli Lilly and Company, Indianapolis, IN, USA), is a selective NET inhibitor that increases synaptic levels of NE and DA in brain regions with low DAT expression. ${ }^{33,48}$ Approved in 2006, atomoxetine was the first nonstimulant approved for ADHD. Two meta-analyses (one examined $28 \mathrm{RCT}$ 
with $n=4,689$, the other examined nine RCT $n=2,762$ ) have indicated that atomoxetine has similar efficacy to immediate-release methylphenidate but is inferior to XR formulations of methylphenidate and amphetamines, such as lisdexamfetamine. ${ }^{49,50}$ The most common adverse effects with atomoxetine are nausea, dry mouth, and anorexia.

Similar to the stimulant medications for ADHD, atomoxetine has been associated with an elevation in blood pressure and heart rate, but the clinical significance of this elevation in children and adolescents is unclear. ${ }^{51}$ Even though atomoxetine does not have an abuse potential, atomoxetine is associated with suicide ideation in children and adolescents and, consequently, has an FDA-designated "black box" warning. ${ }^{52}$ Clonidine [ $N$-(2,6-dichlorophenyl)-4, 5 -dihydro- $1 H$-imidazol-2-amine] is a centrally acting an adrenergic- $\alpha_{2}$ - and I1-imidazoline-receptor agonist. ${ }^{53}$ The adrenergic $\alpha_{2}$ receptors are autoreceptors that presynaptically regulate synaptic vesicle release of norepinephrine. The improvements in attention and reduction of impulsive behaviors with clonidine are mediated by actions on postsynaptic $\alpha_{2}$-adrenergic receptors (non-NE neurons) in the prefrontal cortex, but clonidine also modulates NE release by inhibitory actions on LC-NE neurons. ${ }^{54}$ Clonidine XR formulation, also known as Kapvay ${ }^{\circledR}$ (Shionogi Pharma, Inc., Atlanta, GA, USA), was approved by the FDA in 2010. Notably, clonidine $\mathrm{XR}$ is approved as a monotherapy or in combination with other ADHD medications. Clonidine XR as a monotherapy was evaluated in an 8-week placebo-controlled RCT in children and adolescents $(\mathrm{n}=236)$ with ADHD. ${ }^{55}$ The two doses (0.2 $\mathrm{mg}$ and $0.4 \mathrm{mg} \mathrm{QD})$, compared with placebo, significantly reduced total ratings of the ADHD rating scale (ADHD-RS), which is a scale dependent on parent rating of hyperactivity and inattentive behaviors scored by a clinician. There were no differences in ADHD-RS between the doses of clonidine XR. The most common treatment-emergent adverse effects were somnolence $(39.5 \%$ for $0.2 \mathrm{mg} ; 30.8 \%$ for $0.4 \mathrm{mg}$ ) and fatigue ( $15.8 \%$ for $0.2 \mathrm{mg} ; 12.8 \%$ for $0.4 \mathrm{mg}$ ). Although these symptoms were mild or moderate in severity, they were the major reasons for discontinuation. Sedative effects of clonidine were also associated with sinus bradycardia $(<55$ beats/minute in $6-11$ years old; $<50$ beats/minute in $12-17$ years old) in $21 \%$ of the treated groups. ${ }^{55}$ Clonidine $\mathrm{XR}$ as an adjuvant therapy has been shown to improve stimulant (methylphenidate or amphetamine formulations) clinical efficacy in children and adolescents who were classified as either nonresponders or poor responders to stimulant alone therapy. ${ }^{56}$ Clonidine XR in combination with a stimulant slightly decreased the blood pressure, whereas a stimulant alone produced either no change or a slight increase in blood pressure. ${ }^{56}$ Notwithstanding, hypotension and bradycardia should be monitored with clonidine XR either as a monotherapy or when prescribed with a stimulant. ${ }^{57}$

\section{Guanfacine: mechanism of action and other indications}

Similar to clonidine, guanfacine ( $N$-(diaminomethylidene)2-(2,6-dichlorophenyl) acetamide) is a centrally acting $\alpha_{2}$ adrenergic receptor agonist. Rather than having agonist actions at all three subtypes $\alpha_{2}$ receptors $\left(\alpha_{2 \mathrm{~A}}, \alpha_{2 \mathrm{~B}}\right.$, and $\left.\alpha_{2 \mathrm{C}}\right)$ like clonidine, guanfacine is a selective agonist for the $\alpha_{2 \mathrm{~A}}$ adrenergic receptor. Guanfacine is $\sim 60$-fold more selective for the $\alpha_{2 \mathrm{~A}}$ receptor than $\alpha_{2 \mathrm{~B}}$ receptor. ${ }^{58}$ As determined by selective ligand autoradiography in postmortem human tissue, the predominant $\alpha_{2}$ receptors in the brain are the $\alpha_{2 \mathrm{~A}}$ adrenergic receptor. ${ }^{59}$ In the prefrontal cortex, the $\alpha_{2 \mathrm{~A}}$ adrenergic receptor and the hyperpolarization-activated cyclic nucleotide-gated channels are colocalized on the spines or shaft of dendrites of pyramidal neurons.$^{60}$ Stimulation of the $\alpha_{2 \mathrm{~A}}$ adrenergic receptor inhibits cAMP from closing the hyperpolarization-activated cyclic nucleotide-gated channels, which strengthens cortical neuronal signaling. ${ }^{60}$ In vivo imaging has demonstrated that guanfacine specifically increases frontal and central cortices activities. ${ }^{61} \mathrm{In}$ a within-subjects design study using four young adult nonhuman primates (Macaca mulatta) guanfacine $(0.7 \mathrm{mg} / \mathrm{kg})$ compared with saline increased dorsolateral prefrontal cortex regional blood flow and improved spatial working memory performance in responses. ${ }^{62}$ Guanfacine also increased activation of the dorsolateral prefrontal cortex in human subjects without $\mathrm{ADHD}(\mathrm{n}=16)$ as measured by functional MRI during a behavioral-related reaction time task. ${ }^{63}$ It also appears that $\alpha_{2 \mathrm{~A}}$ receptor mediates the hypothermic, hypotensive, and bradycardia effects of clonidine. ${ }^{64,65}$ Indeed, immediate-release guanfacine, also known as Tenex ${ }^{\circledR}$ (Promius Pharma, LLC, Bridgewater, NJ, USA) was approved as an antihypertensive monotherapy or adjuvant therapy to other antihypertensive agents by the FDA in 1986. Tenex is not recommended for use in children under 12 years old. ${ }^{57}$ Treatment-induced hallucinations have been reported in pediatric patients treated with immediate-release guanfacine. ${ }^{66}$ Guanfacine XR, also known as Intuniv ${ }^{\circledR}$ (Shire Pharmaceuticals), was approved by the FDA in 2009 for the treatment of ADHD in children and adolescents (6-17 years old). Guanfacine XR, similar to clonidine $\mathrm{XR}$, is approved for use as a monotherapy and as a adjuvant therapy to stimulant use for ADHD in children and adolescents. ${ }^{67}$ 


\section{Clinical use of guanfacine $\mathbf{X} \mathbf{R}$}

The safety, efficacy, and dose optimization of guanfacine XR as a monotherapy have been assessed in six RCT; ${ }^{68-73}$ details of these studies have been recently reviewed elsewhere. ${ }^{74,75}$ Pooled data from two $\mathrm{RCT}^{68,72}$ were reanalyzed to determine the efficacy of guanfacine XR for each ADHD subtype ${ }^{76}$ From this dataset, the percentage of ADHD-I was $25.3 \%-27.5 \%$, ADHD-H was $1.8 \%-2 \%$, and ADHD-C was $70.5 \%-72.9 \%$. Both RCT were designed in a similar fashion in that subjects were randomly assigned to receive guanfacine $\mathrm{XR}(\mathrm{n}=490$; 1-4 mg QD) or placebo ( $\mathrm{n}=141)$ for 8 weeks or 9 weeks, and ADHD-RS-IV was assessed from pretreatment baseline and between treatment groups. The discontinuation rate was similar between guanfacine XR and placebo, $63.1 \%$ and $64.7 \%$ of subjects completed the study, respectively. In the guanfacine XR groups, the adverse events that led to discontinuation ( $\%$ frequency in treated population) were somnolence $(3.7 \%)$, sedation $(2.1 \%)$, fatigue $(1.6 \%)$, headache $(1 \%)$, hypotension $(0.8 \%)$, and dizziness $(0.6 \%)$. Decreases in diastolic pressure, prolonged corrected QT, affect liability, depression, and upper abdominal pain were all reported at $0.4 \% .{ }^{76}$ Guanfacine XR significantly reduced ADHD-RS-IV scores in ADHD-I and ADHD-C subjects. In ADHD-I, there was a placebosubtracted reduction of 5.5 least square mean (LSM) from baseline $(P<0.01)$, whereas in the ADHD-C subjects, there was an 8.6 LSM reduction from baseline $(P<0.001)$. In both ADHD-I and ADHD-C, significant improvements were seen at 3 weeks posttreatment. As result of the low number $(n=12)$ of ADHD-H subjects, data analysis was restricted to ADHD-I and ADHD-C subjects. Because improvements were seen in inattentive as well as hyperactive/impulsive symptoms, this supports the notion that guanfacine XR is strengthening cortical networks to improve ADHD behaviors rather than improving ADHD outcomes through sedative effects. The major finding of this post hoc study is that guanfacine XR as monotherapy is clinically effective in reducing the core symptoms across the ADHD subtypes.

Guanfacine XR appears to have a similar safety and tolerance profile to atomoxetine, but guanfacine XR appears to be superior in reducing the core symptoms of ADHD. ${ }^{77}$ In a RCT, subjects $(6-17$ years old; $n=272)$ were randomly assigned guanfacine XR (1-7 mg QD), atomoxetine (10-100 mg QD), or placebo for 4 weeks (or 7 weeks over the age of 13 years). The percentages of ADHD subtypes were ADHD-I (8.9\%-13.2\%), ADHD-H (2.7\%-5.3\%), and ADHD-C (81.6\%-88.4\%). The discontinuation rate was similar for all three treatments $(17.1 \%-20.9 \%)$. However, the percentage of treatment-emergent adverse events that led to discontinuation was higher in guanfacine XR (7.9\%) than atomoxetine $(4.5 \%)$ and placebo $(0.9 \%)$. Two serious treatment-related adverse events, both due to syncope, were reported with guanfacine XR $(n=1)$ and placebo $(n=1)$. The most commonly reported treatment-emergent adverse effects ( $\%$ frequency in treated population) with guanfacine $\mathrm{XR}$ were somnolence (43.9\%), headache (26.3\%), and fatigue (25.4\%), whereas decreased appetite (27.7\%), nausea (26.8\%), fatigue (21.4\%), and headache (19.6\%) were reported with atomoxetine. Headache $(24.3 \%)$ was also the most commonly reported adverse effect in the placebo group. At the end of treatment ( 7 weeks or 10 weeks depending on the age group), guanfacine XR had a placebo-adjusted LSM difference in ADHD-RS-IV of $-8.9(P<0.001)$ compared with atomoxetine, which had a placebo-adjusted LSM difference in ADHD-RS-IV of $-3.8(P<0.05)$. Following these differences, the subscale scores for hyperactivity/impulsivity and inattentive behaviors were more improved with guanfacine XR with an approximate reduction of -4.4 , compared with atomoxetine with an approximate reduction of -1.8 . Significant improvements in ADHD-RS-IV scoring were achieved sooner with guanfacine XR treatment (week 1) compared with atomoxetine treatment (week 3 ) ${ }^{77}$ This study provides support that guanfacine XR as a monotherapy has better efficacy than atomoxetine in improving ADHDrelated behaviors in children and adolescents over a 7- to 10 -week treatment period. It is important to note that this Shire-sponsored (manufacturer of guanfacine XR) study did not provide a longer assessment of treatment improvements and adherence and was designed to make comparisons with the placebo-treated group and not directly (ie, a withinsubjects "cross-over design") between atomoxetine and guanfacine XR.

Because guanfacine is a selective $\alpha_{2 \mathrm{~A}}$ receptor agonist and clonidine is an agonist at all $\alpha_{2}$ receptor subtypes, this might imply that guanfacine XR is more efficacious or has a better safety profile than clonidine XR in treating ADHD To date, there is no study directly supporting the assertion that guanfacine XR is superior to clonidine XR in a head-to-head comparison. However, a meta-analysis (12 RCT; $n=2,276)$ examined the effectiveness of $\alpha_{2}$ receptor agonists (guanfacine and clonidine) as a monotherapy and as an adjuvant for stimulant treatment of ADHD in children and adolescents. ${ }^{78}$ As a monotherapy, clonidine XR and guanfacine XR performed equally well at reducing the ADHD symptoms compared with placebo (nine RCT with average treatment duration was 9.7 weeks). Guanfacine XR was not different than placebo in dropout due to intolerability, but clonidine XR had 
significantly more cases of intolerability-induced dropout than placebo. Fatigue and somnolence were more commonly reported with clonidine XR and guanfacine XR than with placebo. Guanfacine XR also was more often accompanied with sedation and had a prolonged QTcF interval (mean $5.3 \mathrm{~ms}$ ) on ECG than placebo. ${ }^{78}$ Comparing clonidine XR and guanfacine $\mathrm{XR}$ as an adjuvant ("add-on") to stimulant therapy, both were effective at reducing the ADHD symptoms compared with placebo (three RCT with average treatment duration was 7.7 weeks). In addition, guanfacine XR was associated with patients reporting at least one adverse effect (somnolence; $\mathrm{RR}=2.97, P<0.001$ ), whereas clonidine $\mathrm{XR}$ was not. Both clonidine $\mathrm{XR}$ and guanfacine $\mathrm{XR}$ as an adjuvant to stimulants altered hemodynamic endpoints. Specifically, clonidine XR lowered the heart rate 1.1 beats $/ \min (P=0.01)$ and decreased the systolic blood pressure $(P=0.02)$. Guanfacine XR lowered the heart rate by 6.8 beats $/ \min (P<0.0001)$ and decreased the systolic blood pressure $(P=0.0004)$ and the diastolic blood pressure $(P=0.0002)$. Most notably, as a monotherapy, these hemodynamic effects were not significantly altered for either guanfacine XR or clonidine XR. ECG measurements were not performed in the adjuvant studies. It also should be noted that $\mathrm{XR}$ formulations outperformed the immediate-release formulations of clonidine and guanfacine on efficacy outcomes. ${ }^{78}$ These findings suggest that either as a monotherapy or a adjuvant therapy, guanfacine XR improves ADHD outcomes. The somnolence associated with guanfacine XR was not improved by add-on to stimulant therapy. The hemodynamic effects of $\alpha_{2}$-receptor agonists, more so with guanfacine XR, appeared to be exacerbated when combined with a stimulant. Further studies are needed to determine, which stimulant (ie, methylphenidate, amphetamines salts, or lisdexamfetamine) interact with $\alpha_{2}$-receptor agonists to exacerbate the adverse cardiovascular effects. Overall, from the available data, it seems that guanfacine XR and clonidine XR have equivalent efficacy in treating ADHD. While guanfacine XR is more associated with somnolence and adverse cardiovascular effects, the clinical relevance of these effects is not known. It appears that guanfacine XR is better tolerated than clonidine $\mathrm{XR}$, since intolerability-associated discontinuation rates were higher in clonidine XR. This assertion, however, needs to be tested with more long-term data.

\section{Guanfacine $\mathbf{X}$ and patient adherence}

The discontinuation rate of ADHD medications after 1 year of treatment is estimated to be $25 \%-40 \%$ with adolescents ( $>15$ years old) showing the largest discontinuation rate..$^{50,79}$
Guanfacine XR appears to be consistent with this rate. From the available data, the major reasons for discontinuation of guanfacine XR are somnolence and sedation. It appears that these adverse effects are not reduced when guanfacine XR is given at night or as an adjuvant to stimulant therapy. ${ }^{80}$ Morning or evening dosing does not alter the effectiveness of guanfacine in improving ADHD outcomes. ${ }^{80}$ As such, the decision to take the once-a-day tablet in the morning or evening is dependent on the patient, caregiver, or recommendation of the health care provider. Guanfacine XR is also not reported to have the adverse psychiatric events that have been associated with immediate-release guanfacine. ${ }^{66}$ In a postmarketing adverse event reviewed by the FDA guanfacine XR was associated with nine cases of psychiatric events ${ }^{81}$ In eight of the nine cases, guanfacine XR was indicated for ADHD, and in the other one case, the indication was for hyperactivity/aggression/opposition. In the most severe, which were mania-related events, all were from a single center and patients had a medical or family risk factor for bipolar disorder. In all case reports of psychiatric events, the symptoms were resolved or mitigated with discontinuation, down-titration, or behavioral intervention. ${ }^{81}$ Guanfacine XR is not labeled for and is not associated with severe psychiatric adverse effects. ${ }^{67}$ One issue that is associated with discontinuation of guanfacine XR treatment is a compensatory increase in systolic and diastolic blood pressures, which may be observed up to 26 weeks following the final dose. ${ }^{67}$

\section{Conclusion}

Several pharmacotherapy options are available for ADHD. Patient preference and adherence to one medication or a combination of medications are largely based on the different subtypes and heterogeneous presentation of ADHD. Guanfacine XR is a safe and well-tolerated therapeutic option for the treatment of ADHD (Table 1). Like other nonstimulants, guanfacine XR does not have an abuse potential and has the benefit to be combined with other stimulant ADHD medications. Guanfacine XR works on improving central noradrenergic signaling to enhance working memory, whereas stimulants act, in part, on the midbrain DA system to strengthen the deficits of reward processing in ADHD. Future studies are needed to determine the most appropriate pairing of stimulant and guanfacine XR to improve patient adherence and long-term treatment outcomes.

\section{Acknowledgment}

Dr Kathy Manger provided editorial assistance. 
Table I Drug summary and patient adherence

\begin{tabular}{ll}
\hline Drug name & Manufacturer \\
Chemical structure &
\end{tabular}

Abbreviations: $X R$, extended release; $A D H D$, attention deficit hyperactivity disorder; $Q D$, one a day.

\section{Disclosure}

NT Bello was a consultant for Shire Pharmaceuticals for lisdexamfetamine for binge-eating disorder. There are no other financial disclosures or conflicts of interest in this work.

\section{References}

1. Ford T, Goodman R, Meltzer H. The British child and adolescent mental health survey 1999: the prevalence of DSM-IV disorders. J Am Acad Child Adolesc Psychiatry. 2003;42(10):1203-1211.

2. Sayal K, Ford T, Goodman R. Trends in recognition of and service use for attention-deficit hyperactivity disorder in Britain, 1999-2004. Psychiatr Serv. 2010;61(8):803-810.

3. American Psychiatric Association, American Psychiatric Association. DSM-5 Task Force. Diagnostic and Statistical Manual of Mental Disorders: DSM-5. 5th ed. Washington, DC: American Psychiatric Association; 2013.

4. Vande Voort JL, He JP, Jameson ND, Merikangas KR. Impact of the DSM-5 attention-deficit/hyperactivity disorder age-of-onset criterion in the US adolescent population. J Am Acad Child Adolesc Psychiatry. 2014;53(7):736-744.

5. Willcutt EG. The prevalence of DSM-IV attention-deficit/hyperactivity disorder: a meta-analytic review. Neurotherapeutics. 2012;9(3): 490-499.

6. Bloom B, Jones LI, Freeman G. Summary health statistics for U.S. children: National Health Interview Survey, 2012. Vital Health Stat. 2013; 10(258):1-81.

7. Polanczyk G, de Lima MS, Horta BL, Biederman J, Rohde LA. The worldwide prevalence of ADHD: a systematic review and metaregression analysis. Am J Psychiatry. 2007;164(6):942-948.

8. Polanczyk GV, Salum GA, Sugaya LS, Caye A, Rohde LA. Annual research review: a meta-analysis of the worldwide prevalence of mental disorders in children and adolescents. J Child Psychol Psychiatry. 2015;56(3):345-365.

9. Polanczyk G, Rohde LA. Epidemiology of attention-deficit/hyperactivity disorder across the lifespan. Curr Opin Psychiatry. 2007;20(4): 386-392.

10. Froehlich TE, Lanphear BP, Epstein JN, Barbaresi WJ, Katusic SK, Kahn RS. Prevalence, recognition, and treatment of attention-deficit/ hyperactivity disorder in a national sample of US children. Arch Pediatr Adolesc Med. 2007;161(9):857-864.
11. Franke B, Neale BM, Faraone SV. Genome-wide association studies in ADHD. Hum Genet. 2009;126(1):13-50.

12. Faraone SV, Perlis RH, Doyle AE, et al. Molecular genetics of attention-deficit/hyperactivity disorder. Biol Psychiatry. 2005;57(11): 1313-1323.

13. Sprich S, Biederman J, Crawford MH, Mundy E, Faraone SV. Adoptive and biological families of children and adolescents with ADHD. J Am Acad Child Adolesc Psychiatry. 2000;39(11):1432-1437.

14. Hawi Z, Cummins TD, Tong J, et al. The molecular genetic architecture of attention deficit hyperactivity disorder. Mol Psychiatry. 2015; 20(3):289-297.

15. Salatino-Oliveira A, Genro JP, Polanczyk G, et al. Cadherin-13 gene is associated with hyperactive/impulsive symptoms in attention/deficit hyperactivity disorder. Am JMed Genet B Neuropsychiatr Genet. 2015; 168B(3):162-169.

16. Lesch KP, Merker S, Reif A, Novak M. Dances with black widow spiders: dysregulation of glutamate signalling enters centre stage in ADHD. Eur Neuropsychopharmacol. 2012;23(6):479-491.

17. Sagvolden T, Johansen EB, Aase H, Russell VA. A dynamic developmental theory of attention-deficit/hyperactivity disorder (ADHD) predominantly hyperactive/impulsive and combined subtypes. Behav Brain Sci. 2005;28(3):397-419. [discussion 419-368].

18. Hasue RH, Shammah-Lagnado SJ. Origin of the dopaminergic innervation of the central extended amygdala and accumbens shell: a combined retrograde tracing and immunohistochemical study in the rat. J Comp Neurol. 2002;454(1):15-33.

19. Oades RD, Halliday GM. Ventral tegmental (A10) system: neurobiology. 1. Anatomy and connectivity. Brain Res. 1987;434(2): 117-165.

20. Schultz W. Getting formal with dopamine and reward. Neuron. 2002; 36(2):241-263.

21. Johansen EB, Killeen PR, Russell VA, et al. Origins of altered reinforcement effects in ADHD. Behav Brain Funct. 2009;5:7.

22. Sagvolden T, Aase H, Zeiner P, Berger D. Altered reinforcement mechanisms in attention-deficit/hyperactivity disorder. Behav Brain Res. 1998;94(1):61-71.

23. Paloyelis Y, Asherson P, Kuntsi J. Are ADHD symptoms associated with delay aversion or choice impulsivity? A general population study. J Am Acad Child Adolesc Psychiatry. 2009;48(8):837-846.

24. Paloyelis Y, Mehta MA, Faraone SV, Asherson P, Kuntsi J. Striatal sensitivity during reward processing in attention-deficit/hyperactivity disorder. J Am Acad Child Adolesc Psychiatry. 2012;51(7):722e-732e, 729. 
25. Plichta MM, Vasic N, Wolf RC, et al. Neural hyporesponsiveness and hyperresponsiveness during immediate and delayed reward processing in adult attention-deficit/hyperactivity disorder. Biol Psychiatry. 2009;65(1):7-14.

26. Foote SL, Bloom FE, Aston-Jones G. Nucleus locus ceruleus: new evidence of anatomical and physiological specificity. Physiol Rev. 1983; 63(3):844-914.

27. Aston-Jones G, Rajkowski J, Cohen J. Locus coeruleus and regulation of behavioral flexibility and attention. Prog Brain Res. 2000;126: 165-182.

28. Cohen-Yavin I, Yoran-Hegesh R, Strous RD, Kotler M, Weizman A, Spivak B. Efficacy of reboxetine in the treatment of attention-deficit/ hyperactivity disorder in boys with intolerance to methylphenidate: an open-label, 8-week, methylphenidate-controlled trial. Clin Neuropharmacol. 2009;32(4):179-182.

29. Stahl SM. The prefrontal cortex is out of tune in attention-deficit/ hyperactivity disorder. J Clin Psychiatry. 2009;70(7):950-951.

30. Sara SJ. Learning by neurones: role of attention, reinforcement and behaviour. C R Acad Sci. 1998;321(2-3):193-198.

31. Berridge $\mathrm{CW}$, Waterhouse $\mathrm{BD}$. The locus coeruleus-noradrenergic system: modulation of behavioral state and state-dependent cognitive processes. Brain Res Brain Res Rev. 2003;42(1):33-84.

32. Devilbiss DM, Berridge CW. Low-dose methylphenidate actions on tonic and phasic locus coeruleus discharge. J Pharmacol Exp Ther. 2006;319(3):1327-1335.

33. Carboni E, Silvagni A. Dopamine reuptake by norepinephrine neurons: exception or rule? Crit Rev Neurobiol. 2004;16(1-2):121-128.

34. Miner LH, Schroeter S, Blakely RD, Sesack SR. Ultrastructural localization of the norepinephrine transporter in superficial and deep layers of the rat prelimbic prefrontal cortex and its spatial relationship to probable dopamine terminals. J Comp Neurol. 2003;466(4):478-494.

35. Vanicek T, Spies M, Rami-Mark C, et al. The norepinephrine transporter in attention-deficit/hyperactivity disorder investigated with positron emission tomography. JAMA Psychiatry. 2014;71(12):1340-1349.

36. Ding YS, Singhal T, Planeta-Wilson B, et al. PET imaging of the effects of age and cocaine on the norepinephrine transporter in the human brain using (S,S)-[(11)C]O-methylreboxetine and HRRT. Synapse. 2010; 64(1):30-38.

37. Simmler LD, Rickli A, Schramm Y, Hoener MC, Liechti ME. Pharmacological profiles of aminoindanes, piperazines, and pipradrol derivatives. Biochem Pharmacol. 2014;88(2):237-244.

38. Hannestad J, Gallezot JD, Planeta-Wilson B, et al. Clinically relevant doses of methylphenidate significantly occupy norepinephrine transporters in humans in vivo. Biol Psychiatry. 2010;68(9):854-860.

39. van de Giessen E, Booij J. The SPECT tracer [123I]ADAM binds selectively to serotonin transporters: a double-blind, placebo-controlled study in healthy young men. Eur J Nucl Med Mol Imaging. 2010;37(8): 1507-1511.

40. Punja S, Zorzela L, Hartling L, Urichuk L, Vohra S. Long-acting versus short-acting methylphenidate for paediatric ADHD: a systematic review and meta-analysis of comparative efficacy. BMJ Open. 2013;3:3.

41. Khajehpiri Z, Mahmoudi-Gharaei J, Faghihi T, Karimzadeh I, Khalili H, Mohammadi M. Adverse reactions of methylphenidate in children with attention deficit-hyperactivity disorder: report from a referral center. J Res Pharm Pract. 2014;3(4):130-136.

42. Miller GM. The emerging role of trace amine-associated receptor 1 in the functional regulation of monoamine transporters and dopaminergic activity. J Neurochem. 2011;116(2):164-176.

43. Viggiano D, Ruocco LA, Arcieri S, Sadile AG. Involvement of norepinephrine in the control of activity and attentive processes in animal models of attention deficit hyperactivity disorder. Neural Plast. 2004; 11(1-2):133-149.

44. Goodman DW. Lisdexamfetamine dimesylate: the first prodrug stimulant. Psychiatry (Edgmont). 2007;4(8):39-45.

45. Faraone SV, Biederman J, Roe C. Comparative efficacy of Adderall and methylphenidate in attention-deficit/hyperactivity disorder: a metaanalysis. J Clin Psychopharmacol. 2002;22(5):468-473.
46. Manos MJ, Short EJ, Findling RL. Differential effectiveness of methylphenidate and Adderall in school-age youths with attention-deficit/ hyperactivity disorder. J Am Acad Child Adolesc Psychiatry. 1999; 38(7):813-819.

47. Faraone SV, Upadhyaya HP. The effect of stimulant treatment for ADHD on later substance abuse and the potential for medication misuse, abuse, and diversion. J Clin Psychiatry. 2007;68(11):e28.

48. Stahl SM. Neurotransmission of cognition, part 3. Mechanism of action of selective NRIs: both dopamine and norepinephrine increase in prefrontal cortex. J Clin Psychiatry. 2003;64(3):230-231.

49. Hanwella R, Senanayake M, de Silva V. Comparative efficacy and acceptability of methylphenidate and atomoxetine in treatment of attention deficit hyperactivity disorder in children and adolescents: a meta-analysis. BMC Psychiatry. 2011;11:176.

50. Stuhec M, Munda B, Svab V, Locatelli I. Comparative efficacy and acceptability of atomoxetine, lisdexamfetamine, bupropion and methylphenidate in treatment of attention deficit hyperactivity disorder in children and adolescents: a meta-analysis with focus on bupropion. J Affect Disord. 2015;178:149-159.

51. Awudu GA, Besag FM. Cardiovascular effects of methylphenidate, amphetamines and atomoxetine in the treatment of attention-deficit hyperactivity disorder: an update. Drug Saf. 2014;37(9):661-676.

52. Bangs ME, Tauscher-Wisniewski S, Polzer J, et al. Meta-analysis of suicide-related behavior events in patients treated with atomoxetine. J Am Acad Child Adolesc Psychiatry. 2008;47(2):209-218.

53. de Jonge A, Timmermans PB, van Zwieten PA. Quantitative aspects of alpha adrenergic effects induced by clonidine-like imidazolidines. I. Central hypotensive and peripheral hypertensive activities. J Pharmacol Exp Ther. 1982;222(3):705-711.

54. Sallee FR. The role of alpha2-adrenergic agonists in attention-deficit/ hyperactivity disorder. Postgrad Med. 2010;122(5):78-87.

55. Jain R, Segal S, Kollins SH, Khayrallah M. Clonidine extendedrelease tablets for pediatric patients with attention-deficit/hyperactivity disorder. J Am Acad Child Adolesc Psychiatry. 2011;50(2): 171-179.

56. Kollins SH, Jain R, Brams M, et al. Clonidine extended-release tablets as add-on therapy to psychostimulants in children and adolescents with ADHD. Pediatrics. 2011;127(6):e1406-e1413.

57. Shionogi Pharma I. KAPVAY (clonidine hydrochloride) extendedrelease tablets, oral. [Package Insert]; 2010.

58. Uhlen S, Wikberg JE. Delineation of rat kidney alpha 2A- and alpha 2B-adrenoceptors with $[3 \mathrm{H}] \mathrm{RX} 821002$ radioligand binding: computer modelling reveals that guanfacine is an alpha $2 \mathrm{~A}$-selective compound. Eur J Pharmacol. 1991;202(2):235-243.

59. Sastre M, Garcia-Sevilla JA. Alpha 2-adrenoceptor subtypes identified by $[3 \mathrm{H}] \mathrm{RX} 821002$ binding in the human brain: the agonist guanoxabenz does not discriminate different forms of the predominant alpha $2 \mathrm{~A}$ subtype. J Neurochem. 1994;63(3):1077-1085.

60. Wang M, Ramos BP, Paspalas CD, et al. Alpha2A-adrenoceptors strengthen working memory networks by inhibiting cAMPHCN channel signaling in prefrontal cortex. Cell. 2007;129(2): 397-410.

61. Swartz BE, Kovalik E, Thomas K, Torgersen D, Mandelkern MA. The effects of an alpha-2 adrenergic agonist, guanfacine, on $\mathrm{rCBF}$ in human cortex in normal controls and subjects with focal epilepsy. Neuropsychopharmacology. 2000;23(3):263-275.

62. Avery RA, Franowicz JS, Studholme C, van Dyck CH, Arnsten AF. The alpha-2A-adrenoceptor agonist, guanfacine, increases regional cerebral blood flow in dorsolateral prefrontal cortex of monkeys performing a spatial working memory task. Neuropsychopharmacology. 2000; 23(3):240-249.

63. Clerkin SM, Schulz KP, Halperin JM, et al. Guanfacine potentiates the activation of prefrontal cortex evoked by warning signals. Biol Psychiatry. 2009;66(4):307-312.

64. Gyires K, Zadori ZS, Torok T, Matyus P. alpha(2)-Adrenoceptor subtypes-mediated physiological, pharmacological actions. Neurochem Int. 2009;55(7):447-453. 
65. Franowicz JS, Arnsten AF. Actions of alpha-2 noradrenergic agonists on spatial working memory and blood pressure in rhesus monkeys appear to be mediated by the same receptor subtype. Psychopharmacology (Berl). 2002;162(3):304-312.

66. Boreman CD, Arnold LE. Hallucinations associated with initiation of guanfacine. J Am Acad Child Adolesc Psychiatry. 2003;42(12):1387.

67. Shire. INTUNIV (guanfacine) extended-release tablets. [Package Insert]; 2009

68. Biederman J, Melmed RD, Patel A, et al; SPD503 Study Group. A randomized, double-blind, placebo-controlled study of guanfacine extended release in children and adolescents with attention-deficit/ hyperactivity disorder. Pediatrics. 2008;121(1):e73-e84.

69. Connor DF, Findling RL, Kollins SH, et al. Effects of guanfacine extended release on oppositional symptoms in children aged 6-12 years with attention-deficit hyperactivity disorder and oppositional symptoms: a randomized, double-blind, placebo-controlled trial. CNS Drugs. 2010;24(9):755-768

70. Kollins SH, López FA, Vince BD, et al. Psychomotor functioning and alertness with guanfacine extended release in subjects with attentiondeficit/hyperactivity disorder. J Child Adolesc Psychopharmacol. 2011; 21(2):111-120.

71. Newcorn JH, Stein MA, Childress AC, et al. Randomized, double-blind trial of guanfacine extended release in children with attention-deficit/ hyperactivity disorder: morning or evening administration. J Am Acad Child Adolesc Psychiatry. 2013;52(9):921-930.

72. Sallee FR, McGough J, Wigal T, Donahue J, Lyne A, Biederman J. Guanfacine extended release in children and adolescents with attentiondeficit/hyperactivity disorder: a placebo-controlled trial. J Am Acad Child Adolesc Psychiatry. 2009;48(2):155-165.

73. Scahill L, Chappell PB, Kim YS, et al. A placebo-controlled study of guanfacine in the treatment of children with tic disorders and attention deficit hyperactivity disorder. Am J Psychiatry. 2001;158(7): 1067-1074.
74. Rizzo R, Martino D. Guanfacine for the treatment of attention deficit hyperactivity disorder in children and adolescents. Expert Rev Neurother. 2015;15(4):347-354.

75. Ruggiero S, Clavenna A, Reale L, Capuano A, Rossi F, Bonati M. Guanfacine for attention deficit and hyperactivity disorder in pediatrics: a systematic review and meta-analysis. Eur Neuropsychopharmacol. 2014; 24(10):1578-1590.

76. Sallee FR, Kollins SH, Wigal TL. Efficacy of guanfacine extended release in the treatment of combined and inattentive only subtypes of attention-deficit/hyperactivity disorder. J Child Adolesc Psychopharmacol. 2012;22(3):206-214.

77. Hervas A, Huss M, Johnson M, et al. Efficacy and safety of extendedrelease guanfacine hydrochloride in children and adolescents with attention-deficit/hyperactivity disorder: a randomized, controlled, phase III trial. Eur Neuropsychopharmacol. 2014;24(12):1861-1872.

78. Hirota T, Schwartz S, Correll CU. Alpha-2 agonists for attention-deficit/ hyperactivity disorder in youth: a systematic review and meta-analysis of monotherapy and add-on trials to stimulant therapy. J Am Acad Child Adolesc Psychiatry. 2014;53(2):153-173.

79. Zetterqvist J, Asherson P, Halldner L, Langstrom N, Larsson H. Stimulant and non-stimulant attention deficit/hyperactivity disorder drug use: total population study of trends and discontinuation patterns 2006-2009. Acta Psychiatr Scand. 2013;128(1):70-77.

80. Young J, Rugino T, Dammerman R, Lyne A, Newcorn JH. Efficacy of guanfacine extended release assessed during the morning, afternoon, and evening using a modified conners' parent rating scale-revised: short form. J Child Adolesc Psychopharmacol. 2014;24(8):435-441.

81. FDA. Intuniv (Guanfacine Extended-Release); Pediatric Post-Marketing Adverse Event Review. Silver Spring: Center for Drug Evaluation and Research; 2011.
Patient Preference and Adherence

\section{Publish your work in this journal}

Patient Preference and Adherence is an international, peer-reviewed, open access journal that focuses on the growing importance of patient preference and adherence throughout the therapeutic continuum. Patient satisfaction, acceptability, quality of life, compliance, persistence and their role in developing new therapeutic modalities and compounds to optimize

\section{Dovepress}

clinical outcomes for existing disease states are major areas of interest for the journal. This journal has been accepted for indexing on PubMed Central. The manuscript management system is completely online and includes a very quick and fair peer-review system, which is all easy to use. Visit http://www. dovepress.com/testimonials.php to read real quotes from published authors. 